\title{
Thorina and thorinum
}

\section{Berzelius}

To cite this article: Berzelius (1830) Thorina and thorinum, Philosophical Magazine Series 2, 7:41, 388-389, DOI: 10.1080/14786443008675313

To link to this article: http://dx.doi.org/10.1080/14786443008675313

曲 Published online: 14 Jul 2009.

Submit your article to this journal 전

III Article views: 2

Q View related articles $₫$ 
tion of the hydrated orange sulphuret. If a current of hydrogen be passed at a low red heat over kermes deprived of moisture by heat, much water and sulphuretted hydrogen are obtained, and the antimony is reduced; but, as already observed, the residue possesses an alkaline re-action. After these various experiments, it is unquestionable that kermes contains oxide and sulphuret of antimony, and it ought to be considered as an oxisulphuret. The quantity of water obtained by decomposing it with hydrogen is variable; but it may be considered as composed of one proportion of protoxide of antimony and two proportions of protosulphuret. In fact, I obtained 0.9 of the proportion of protoxide; and $M$. Henry by another process found the difference still less.

It is equally certain that kermes mineral precipitated from the alkaline sulphurets which held it in solution, is an hydrate. It loses water gradually as the temperature is raised, and appears black when deprived of it ; but in my experiments I did not obtain a definite proportion.

When potash, soda, or their carbonates act upon black sulphuret of antimony, their oxygen goes to the antimony, with which it forms protoxide, and the sulphur of the antimony takes the place of the oxygen of the alkali : thus it is that no kermes is obtained by boiling sulphuret of antimony with sulphuret of potassium saturated with sulphur; but by means of acid, a yellowish orange precipitate is formed in the solution, which when heated yields sulphur and becomes black. The golden sulphuret gives a similar result. - Ann. de Chim. et Phys. tom. xlii. p. 88 .

\section{THORTNA AND THORINUM. BY BERZELIUS.}

In the Phil. Mag. for November last, we noticed Berzelius's discovery of a new earth or rather metallic oxide, to which he gave the name of Thorina: we add the following particulars respecting it. Thorina hardens in the fire, and it becomes difficult to powder it. Its specific gravity is greater than that of any other earth, and almost equal to that of oxide of lead, being 9.402 . It is infusible and unalterable by the blowpipe per se. With borax it dissolves extremely slowly and the resulting glass is not transparent, but it may be so saturated as to become milky on cooling. It dissolves slowly with salt of phosphorus, and carbonate of soda does not dissolve it at all.

One hundred parts of thorina appear to consist of

$$
\begin{aligned}
& \text { Thorina } \ldots \ldots \ldots \ldots \ldots \ldots \\
& \text { Oxygen } \ldots \ldots \ldots \ldots \ldots \ldots \\
& 11 \cdot 84
\end{aligned}
$$

and one hundred parts of hydrate of thorina of

$$
\begin{aligned}
& \text { Thorina } \ldots \ldots \ldots \ldots \ldots \ldots \\
& \text { Water } \ldots \ldots \ldots \ldots \ldots \ldots \\
& \hline 11.75
\end{aligned}
$$

The weight of its atom, according to Berzelius, is 884.9 ; hydrogen being unity, we may perhaps assume it to be 70 .

Thorina is distinguished from other earths principally by its combination with sulphuric acid; in this combination, heat precipitates a salt, which by cooling slowly, but completely, redissolves. It is, however, to be observed with respect to this re-action, that it does not oc- 
cur when those bases are present, with which thorina forms double salts; the latter are but little precipitated by heat. It differs from alumina and glucina, because it is insoluble in caustic potash, which dissolves those substances ; from yttria, because it forms a double salt with sulphate of potash, which is insoluble in a saturated solution of sulphate of potash : this circumstance furnishes a method of separating it from yttria. It differs from zirconia, because the latter, after having been precipitated hot by sulphate of potash, is for the most part insoluble in water and the acids, and because thorina is precipitated by ferrocyanate of potash, and zirconia is not. It differs from the oxide of cerium, in not assuming the same colour when it is dried and burnt, and also in not giving with the blowpipe a coloured compound with salt of phosphorus, or borax, either hot or cold, provided it be not at all mixed with iron.

From titanic acid it is distinguished by its precipitation with sulphate of potash, or by the characteristic manner of that acid with the blowpipe.

From the metallic oxides, properly so called, and with which there is some inducement to place it on account of its great specific gravity, it is distinguished by not being precipitated with sulphuretted hydrogen.-Bibliotheque Universelle, Dec. 1829.

PREPARATION OF MAGNESIUM.

M. Bussy has announced to the French Academy, that he has obtained magnesium or the metallic base of magnesia, and he sent a specimen of the metal; it was procured by the decomposition of the chloride by a process similar to that employed by $M$. Wöhler.

Magnesium has the following properties :-it is brilliant, silvery white, perfectly ductile and malleable, fusible at a moderate temperature, like zinc, volatilized at a temperature a little higher than that of its melting point, and like that metal condenses into small glo. bules. It does not decompose water at common temperatures; it oxidizes at a high temperature, and is slowly converted into magnesia, when in small masses ; but when in filings, it burns with great splendour, throwing out sparks, like iron in oxygen.

M. Bussy is of opinion, that magnesium may be usefully employed in the arts; and he is occupied with endeavouring to find means of procuring it in a simple and ceconomical manner. - Le Globe.

\section{NEW NATIVE COMPOUND OF CARBONATE OF LIME AND CARBO- NA'TE OF SODA.}

This mineral differs from Gay-Lussite, which is a compound of the same salts; it was procured by $M$. Barruel at a mineral dealer's, who did not know its origin. The structure of this substance is laminated, has an easy threefold cleavage, and gives a rhomboid similar to that of carbonate of lime, as nearly as could be discovered by comparing the crystals of these two substances.

The fragments are perfectly transparent; the lustre is vitreous, resembling that of arragonite. It scratches carbonate of lime readily, and arragonite with difficulty. Its sp. gr. is $2 \cdot 921$, and the double refraction 